\title{
Panorama dos Fluxos Migratórios na Dinâmica de Urbanização dos Cerrados Baianos: um olhar para as cidades de Barreiras e Luís Eduardo Magalhães
}

\author{
Migratory Flow Overview of the Urbanization Dynamics in the Savannas of Bahia: a \\ look at the cities of Barreiras and Luís Eduardo Magalhães
}

Aproximación a los Flujos Migratorios en la Dinámica de Urbanización de los Cerrados Baianos: una mirada sobre las ciudades de Barreiras y Luís Eduardo Magalhães

\author{
Elton Andrade dos Santos ${ }^{1}$ \\ https://orcid.org/0000-0003-1344-2222 \\ Agripino Souza Coelho Neto ${ }^{2}$ \\ https://orcid.org/0000-0003-3714-510X
}

\begin{abstract}
RESUMO: A partir da década de 1960, os cerrados brasileiros foram objeto de políticas governamentais que estimularam sua ocupação populacional e sua exploração econômica. As ações da Empresa Brasileira de Pesquisa Agropecuária (EMBRAPA) e do Programa de Cooperação NipoBrasileira para o Desenvolvimento dos Cerrados (PRODECER) foram decisivas para o desenvolvimento de tecnologias que viabilizaram a expansão agrícola nos cerrados, com a introdução da chamada "agricultura moderna", engendrando a atração de expressivos fluxos migratórios. Diante deste quadro, o presente texto se propõe a caracterizar os processos migratórios e as transformações promovidas pela dinâmica na ocupação dos cerrados baianos, tomando como referência as cidades de Barreiras e Luís Eduardo Magalhães. A pesquisa se apoiou em bibliografia especializada sobre migrações e em estudos realizados sobre as chamadas "cidades do agronegócio" no Oeste da Bahia. Ocupou-se, também, de dados secundários do Instituto Brasileiro de Geografia e Estatística (IBGE) e das informações de sites de empresas imobiliárias e de jornais on-line do Oeste da Bahia. Os resultados do processo de ocupação dos cerrados baianos apontaram o crescimento acelerado de cidades, o surgimento de novas cidades, a intensificação do processo de urbanização e a produção de segregação socioespacial.
\end{abstract}

PALAVRAS-CHAVE: Migrações. Cerrados. Crescimento urbano.

\footnotetext{
${ }^{1}$ Mestrando pelo Programa de Pós-Graduação em Estudos Territoriais da Universidade do Estado da Bahia. E-mail: eltonandrade13@gmail.com.

2 Doutor em Geografia pela Universidade Federal Fluminense (UFF). Professor Titular do Departamento de Ciências Exatas e da Terra, da Universidade do Estado da Bahia. E-mail: agscneto@uneb.br.
} 


\begin{abstract}
From the 1960s onwards, the Brazilian savannas ("cerrados") were the object of government policies that stimulated their population occupation and economic exploitation. Initiatives of the Brazilian Agricultural Research Corporation (Embrapa) and the Japanese-Brazilian Cooperation Program for Cerrados Development (Prodecer) were decisive for the development of technologies that enabled agricultural expansion in the savannas through the introduction of the so-called "modern agriculture", attracting expressive migratory flows to those areas. Considering that context, this paper proposes to characterize the migratory processes and the transformations promoted by the occupation dynamics of the savannas in the state of Bahia, in Brazil, using as reference the cities of Barreiras and Luís Eduardo Magalhaes. The research is based on the analysis of specialized bibliography on migrations and studies carried out on the "agribusiness cities" in Western Bahia, on secondary data from the Brazilian Institute of Geography and Statistics (IBGE) and on information from websites of local real estate companies and online newspapers. The results of the occupation process of the savanna area in Bahia pointed to the accelerated growth of cities, the emergence of new cities, the escalation of the urbanization process and the production of socio-spatial segregation.
\end{abstract}

KEYWORDS: Migrations. Cerrados. Urban growth.

RESUMEN: Desde la década de 1960, la sabana brasileña (los "cerrados") ha sido objeto de políticas gubernamentales que estimularon su ocupación poblacional y su explotación económica. Las acciones de la Empresa Brasileña de Investigación Agrícola (EMBRAPA) y del Programa de Cooperación Japonesa-Brasileña para el Desarrollo de los Cerrados (PRODECER) fueron decisivas para la implementación de tecnologías que viabilizaron la expansión agrícola en los cerrados, con la introducción de la llamada "agricultura moderna", generando la atracción de significativos flujos migratorios. En este marco, el presente texto pretende caracterizar los procesos migratorios y las transformaciones promovidas por la dinámica de ocupación de los cerrados bahianos, tomando como referencia las ciudades de Barreiras y de Luis Eduardo Magalháes. La investigación se basó sobre bibliografía especializada en migración y estudios en torno a las denominadas "ciudades agroindustriales" en el oeste de Bahía. También se consideraron los datos secundarios provenientes del Instituto Brasileño de Geografía y Estadística (IBGE) y la información aportada por sitios web de empresas inmobiliarias y periódicos en línea en el oeste de Bahía. Los resultados del proceso de ocupación de los cerrados bahianos promovieron el crecimiento acelerado de las ciudades, el surgimiento de nuevas ciudades, la intensificación del proceso de urbanización y la producción de segregación socioespacial.

PALABRAS-CLAVE: Migraciones. Cerrados. Crecimiento urbano.

\title{
INTRODUÇÃO
}

No século $\mathrm{XX}$, o território brasileiro experimentou grandes fluxos migratórios interregionais, principalmente de natureza rural-urbana, relacionados aos processos de industrialização e urbanização, que ajudaram a conformar grandes metrópoles, porém os movimentos migratórios parecem ter assumido novos contornos no final do século $X X$ e início do século XXI, com a formação de novas cidades e a disseminação de cidades médias. De um lado, as migrações de longa distância redesenharam seus trajetos e seus significados; de outro lado, as dinâmicas regionais passaram a imprimir especificidades às migrações.

As áreas de fronteiras agrícolas, caso dos cerrados baianos, foram objeto de forte expansão da chamada "agricultura moderna" de grãos, sendo verificado um intenso 
processo de urbanização, com o surgimento de novas cidades e o crescimento acelerado de cidades preexistentes.

O presente artigo tem como objetivo caracterizar os processos migratórios e as transformações desencadeadas pela dinâmica na ocupação dos cerrados baianos, tomando como exemplo as duas experiências mais substantivas que se processaram neste recorte regional: os casos das cidades de Barreiras e de Luís Eduardo Magalhães.

A feitura do texto resulta de uma pesquisa que se apoia na bibliografia especializada sobre migrações e em estudos realizados sobre as chamadas "cidades do agronegócio" no Oeste da Bahia. Ocupa-se também de dados secundários do Instituto Brasileiro de Geografia e Estatística (IBGE) e das informações de sites de empresas imobiliárias e de jornais on-line do Oeste da Bahia.

O texto principia com uma breve contextualização das abordagens clássicas que se propuseram a teorizar sobre as migrações. Em seguida, analisa a influência dos fluxos migratórios na ocupação dos cerrados brasileiros. Por fim, apresenta um panorama dos cerrados baianos, apresentando os efeitos da dinâmica migratória que compõem o cenário atual das cidades de Barreiras e de Luís Eduardo Magalhães.

\section{MIGRAÇÕES: UMA BREVE CONTEXTUALIZAÇÃO TEÓRICA}

No contexto dos estudos populacionais, as migrações convivem com a confluência de abordagens e disciplinas que, cada qual com suas preocupações e objetos, compõem um grande quadro sobre os migrantes e seus movimentos, sobre os processos materiais, as consequências e implicações em diferentes escalas, sobre os simbolismos e as transformações culturais (MARANDOLA JÚNIOR; DAL GALLO, 2010). Os variados autores que se debruçam sobre os processos migratórios podem ser agrupados em três perspectivas teóricas: a neoclássica, a histórico-estrutural e a mobilidade da força de trabalho.

A primeira perspectiva, reconhecida como abordagem neoclássica, se preocupa com a economia do espaço e a gestão capitalista da mão de obra. Para esta corrente, as migrações decorrem dos "[...] desequilíbrios espaciais dos fatores de produção: terra, capital e recursos naturais", exercendo assim um papel fundamental na "[...] eliminação dessas mesmas diferenças [regionais, nacionais], atuando como fator corretivo dos desequilíbrios socioeconômicos no espaço" (SALIM, 1992, p. 122-123).

De acordo com Raczynski (1983), essa perspectiva envolve alguns pressupostos básicos: as diferenças de emprego e salário em diferentes áreas, o cálculo de custos e utilidades, a permanência e mudança de local e o somatório das migrações fruto das decisões individuais. 
Um dos primeiros estudos sobre as migrações foi feito por Ernest Ravenstein (1980), investigando as estatísticas oficiais sobre os movimentos internos da população da Inglaterra, culminando na formulação de uma série de leis a respeito do fenômeno. Segundo o estudioso, havia fatores repulsivos e fatores atrativos que atuavam sobre as migrações, sendo que os fatores repulsivos estavam ligados à estrutura e à propriedade da terra, ao sistema de comercialização dos produtos agrícolas e à dispersão de renda.

As leis das migrações enunciadas pelo autor ainda podem ser aplicadas em muitos casos. Elas foram resumidas conforme segue: (a) os deslocamentos dão-se em direção aos centros manufatureiros e comerciais; (b) a maior parte dos migrantes procede de áreas próximas; (c) os naturais de cidades (ou vilas) emigram relativamente menos do que os naturais das áreas rurais; (d) a melhoria dos meios de transporte e de locomoção induz o aumento das migrações; (e) a cada corrente migratória, opõe-se uma contracorrente; (f) predominância de fatores econômicos entre as causas migratórias; e (g) predominância de mulheres nas correntes de pequeno percurso (KLEIN; MASSUQUETTI; SPRICIGO, 2012).

Everett Lee (1980) retoma as discussões sobre a mobilidade populacional, dedicandose principalmente à compreensão dos fatores que produzem a migração, tendo em vista os aspectos presentes no local de origem e no local de destino (modelo push-pull). Lee aprofunda suas reflexões dando ênfase à questão da seletividade migratória, chegando a afirmar que os migrantes não constituem uma amostra aleatória da população, mas sim indivíduos com características pessoais específicas que respondem de maneira diferente a estímulos e obstáculos.

As migrações são seletivas em razão das pessoas responderem de forma diferente à série de fatores positivos e negativos prevalecentes nos locais de origem e de destino, terem capacidades diferentes para superar as séries de obstáculos e diferenciam-se entre si em termos dos fatores pessoais (LEE, 1980, p. 111).

Ao invés da visão da migração como um ato de decisão pessoal, o economista Michael Todaro (1969) elaborou um modelo econômico baseado nas migrações ruralurbanas, considerando os diferenciais previstos de renda na origem e no destino, assim a escolha ficaria na mão do indivíduo que seria o responsável para avaliar o melhor resultado. Como consequência desse fato, haveria um deslocamento de mão de obra do setor rural em direção ao setor urbano, gerando maior concentração da população no setor urbano e aumento do desemprego, visto não ter havido uma política de incentivo para o setor rural.

Até a década de 1970 as ideias da vertente neoclássica predominavam nos estudos sobre as migrações, considerando a mobilidade uma decisão individual. Os movimentos migratórios eram estudados de maneira descritiva e dualista pela mensuração dos fluxos 
demográficos, recebendo críticas de outros estudiosos por ignorar os aspectos sociais, políticos e econômicos que deveriam ser ponderados nas análises (BECKER, 1997).

A partir da década de 1970, em contraposição ao modelo anterior, emerge a perspectiva histórico-estrutural, que trata a migração como um fenômeno social, tendo como elemento importante a concentração espacial e seu caráter histórico. O foco da análise é direcionado para as relações sociais na perspectiva do desenvolvimento das forças produtivas e para os mecanismos de dominação gerados por essas forças (WOOD, 1982). Segundo Marandola Júnior (2011, p. 102-103), a perspectiva neomarxista concebe "[...] a migração como mobilidade forçada, diretamente relacionada à formação de exército trabalhador de reserva, numa perspectiva histórico-estrutural".

Para Paul Singer (1980, p. 212), “[...] as migrações internas são sempre historicamente condicionadas, sendo o resultado de um processo global de mudança, do qual elas não devem ser separadas". Para o autor, as consequências que determinam o fluxo migratório são caracterizadas como rural-urbanas, devido ao processo de desenvolvimento do país.

Com base nas ideias de Singer, os fluxos migratórios ocorrem em virtude dos fatores de atração e expulsão, além da interação de ambos os fatores. Em consequência do aumento dos serviços e da atividade industrial nas grandes cidades, ampliou-se a necessidade por força de trabalho, promovendo também a atração dos migrantes causada pela oferta de empregos, salários e pelas perspectivas de melhores oportunidades não disponíveis em seu local de origem. Os fatores de expulsão foram subdivididos em dois: (1) fatores de mudança, tendo como principal característica a mecanização da agricultura, que resultou no aumento da produção, mas diminuiu a oferta de trabalho em áreas rurais; e (2) fatores de estagnação, cujo principal motivo seriam as dificuldades em se manter no campo, pelo crescimento das áreas cultiváveis para a agricultura, aliadas às pressões relacionadas aos costumes tradicionais, dificultando o crescimento da produtividade.

Apesar de ambas as perspectivas anteriores contribuírem para a concepção e avançarem na discussão das migrações, elas foram objeto de críticas. Segundo Becker (1997), enquanto a abordagem neoclássica centra a compreensão no nível do indivíduo, a perspectiva histórico-estrutural apresenta dificuldade em atuar em diferentes escalas da mesma realidade, limitando-se a padrões e determinações de uma formação social.

Diferentemente das duas perspectivas anteriores, a mobilidade da força de trabalho como terceira perspectiva centra-se na análise da relação capital e trabalho, que se torna o agente de transformação espacial. Sob a ótica de Gaudemar (1976, p. 179), "[...] seria uma forma de justificar todas as políticas de mobilidade forçada, ou seja, a liberdade individual nada mais seria do que mais uma vontade imperante do mercado". O autor destaca que a mobilidade da força de trabalho é compreendida como um fenômeno que promove o 
deslocamento espacial, setorial e profissional do trabalhador, com o objetivo de explorar sua força de trabalho e acumular excedente econômico, assim estaria ligada ao capital e à produtividade do desenvolvimento das forças produtivas.

De acordo com Salim (1992), a mobilidade da força de trabalho conduz ao processo de produção e circulação entre as diferentes esferas de produção. Por conseguinte, enquanto o enfoque neoclássico analisa os reflexos das correntes migratórias, tendo na migração um agente de transformação, na mobilidade da força de trabalho a análise recai sobre as formas concretas de sua mobilidade. Na visão neoclássica, portanto, os problemas estruturais são os possíveis causadores dos deslocamentos e na mobilidade da força de trabalho, e os enfoques recaem no processo de acumulação capitalista.

A intensificação do processo de migrações reproduziu novas formas de estruturação do espaço urbano. A reestruturação do capital (HARVEY, 1992) engendrou uma nova forma social e espacial de organização do sistema produtivo no âmbito mundial, produzindo repercussões diretas e indiretas nos modos de vida e nas possibilidades de escolha das pessoas. As transformações que vieram nos anos 1990, em termos de comunicação e transporte, aumentaram a complexidade e as formas de interações espaciais.

\section{A INFLUÊNCIA DOS FLUXOS MIGRATÓRIOS NA OCUPAÇÃO DOS CERRADOS BRASILEIROS}

Os fluxos migratórios no Brasil sofreram grandes alterações por volta da segunda metade do século XX. Com o fim da II Guerra Mundial, as migrações passaram a se orientar mais para as áreas de avanço da agropecuária (principalmente para as regiões CentroOeste e Norte), mais forte e claramente para as cidades médias. Esta tendência ocorre mesmo internamente nas regiões metropolitanas, com a busca de cidades de menor porte próximas aos grandes centros, em decorrência forte influência dos eixos de mobilidade (OJIMA; MARANDOLA JÚNIOR, 2012).

A década de 1950 foi um período de longos percursos entre a origem e o destino dos migrantes de todo o País, que partiam de áreas rurais estagnadas para regiões metropolitanas, especialmente São Paulo e Rio de Janeiro. Esta foi a década de maior crescimento urbano do Brasil, alimentado pelo grande crescimento natural da população, principalmente das áreas rurais, e pelos grandes projetos de colonização agrícola e de exploração mineral, que induziram uma ocupação desigual, gerando alta mobilidade populacional, provocando o esgotamento dos recursos naturais (RIGOTTI, 2011).

O processo de reestruturação produtiva no país é iniciado a partir do final dos anos 1970, mas nos anos 1990 ganha outra dimensão com a abertura econômica e a política neoliberal. Essa reestruturação acarretou transformações no processo produtivo, na 
organização e gestão do trabalho, bem como na dinâmica do espaço, fortemente associada à circulação de fluxos migratórios para os cerrados. As ações do Estado brasileiro foram decisivas para ocupação dos cerrados, tornando-os a nova fronteira agrícola do país.

Um fator fundamental para esse resultado foi o estímulo que o governo militar concedeu à "ocupação do cerrado" e à expansão da fronteira agrícola, visto que o país adotou uma estratégia de gerar divisas e equilibrar sua balança comercial por meio do aumento de suas exportações (WESZ JUNIOR, 2014, p. 119).

O fluxo migratório da população rural em direção às cidades e vilas ocorreu por muitos fatores, pesando entre eles a importância da industrialização, das grandes obras introduzidas pelo Governo Federal no interior do país, tais como a construção de Brasília, a abertura de rodovias federais e de usinas hidrelétricas, e também, o processo de modernização do campo, que teve, especialmente no Centro-Oeste, um impacto territorial distinto, confirmando a transição do Brasil rural para o urbano (SANTOS, 2016).

O governo federal intensificou as políticas públicas através de créditos financeiros facilitados e de programas agropecuários. A criação da Empresa Brasileira de Pesquisa Agropecuária (EMBRAPA) em 1972 possibilitou o direcionamento de pesquisas das potencialidades agrícolas dos cerrados. Posteriormente à atuação da (EMBRAPA), foi criada uma série de programas e instituições que desenvolveram tecnologias para a expansão agrícola no cerrado, entre elas destacamos o Programa de Cooperação Nipo-Brasileira para o Desenvolvimento dos Cerrados (PRODECER), criada em 1974.

A EMBRAPA teve papel importante no processo de ocupação das áreas de cerrado do Centro-Oeste, Norte e Nordeste do país. As pesquisas desenvolvidas pela EMBRAPA na década de 1970, além de identificarem os fatores limitantes, representados pelas propriedades químicas dos solos, de viabilizarem soluções técnicas (adubação química, mecanização etc.) e apontarem as possibilidades de produção de sementes de grãos adaptáveis e com altos rendimentos, deixavam claro para quem se destinava o investimento na produção científica pelo Estado (BRANDÃO, 2010).

O PRODECER representou uma nova forma de intervenção estatal no direcionamento da fronteira agrícola nacional, implementado pela parceria entre o Japão e o governo militar brasileiro, com financiamento da Agência de Cooperação Internacional Japonesa (JICA) e também de bancos privados do Japão. O Governo Federal responsabilizou-se pela criação das bases para que a acumulação capitalista no setor agrícola pudesse se reproduzir com ampla participação de outros setores organizados do sistema, o capital financeiro e o industrial, principalmente nas áreas de cerrados do país (SANTOS, 2016).

Esse programa ganha destaque pela implantação de 21 projetos, que ocuparam uma área em torno de 353.748 hectares em Minas Gerais, Goiás, Mato Grosso, Mato Grosso do 
Sul, Tocantins, Bahia e Maranhão. O projeto teve três fases: o PRODECER I - 1979-1984, que centrava suas políticas em Minas Gerais; o PRODECER II -1985 - 1993, que concebia uma política de expansão da soja para o Nordeste, começando pela Região Oeste da Bahia, além de Minas Gerais, Mato Grosso, Mato Grosso do Sul e Goiás; o PRODECER III - 1995 - 2001, que avançou ainda mais pelo Nordeste, englobando o Maranhão e o Piauí, incorporando políticas para a região Norte (nos estados do Tocantins, Pará e Rondônia).

A transformação tecnológica e o desenvolvimento da agricultura em bases empresariais provocaram mudanças significativas na estrutura fundiária e produtiva desses espaços, pois os objetivos do programa estavam voltados para a criação de fazendas de grande porte, de agricultores com suporte empresarial e capacidade de utilizar novas tecnologias intensivas em capital (SANTOS, 2007). Essa nova realidade incentivou a migração de produtores do Sul e Sudeste do Brasil, implantando novas características de trabalho e novos costumes, diferentes da população nativa. A chegada desses migrantes acompanhou a expansão das áreas de produção agrícola do Cerrado, concentrou a estrutura fundiária e promoveu o êxodo rural.

A ocupação da fronteira agrícola se prolongou nos anos 1980 com significativas mudanças econômicas, que tiveram rebatimentos sobre os movimentos migratórios, especialmente com a aceleração dos processos de urbanização e de industrialização. Alves (2006) afirma que os agrupamentos de migrantes passam a ocupar as novas fronteiras agrícolas, aproveitando as ações governamentais e o baixo preço das terras, sendo que os sulistas lideraram a corrente migratória para os cerrados baianos e se tornaram os principais responsáveis pela produção de grãos nos cerrados, com destaque para a soja, que vem ganhando cada vez mais importância na pauta das exportações brasileiras.

Nos anos 1990 e início do século XXI, vivemos o processo de desconcentração metropolitana, associada à alteração da distribuição das atividades econômicas, em particular, as industriais, oportunidade em que assistimos a uma complexificação da rede urbana. O sentido de cidade e região é redefinido não a partir da metrópole, mas das cidades pequenas e médias, que passam a se articular de maneira mais intensa sem a mediação metropolitana. Há processos novos que têm se difundido pela rede urbana brasileira, que não são comandados pelas metrópoles, embora, evidentemente, estejam conectados às redes e sistemas que organizam toda a estrutura urbana nacional (OJIMA; MARANDOLA JÚNIOR, 2012).

Uma das consequências da reestruturação produtiva da agropecuária no Brasil, envolvendo as migrações e o processo de urbanização, são as novas relações entre o campo e a cidade, desencadeadas pelas novas necessidades de consumo, com o aparecimento das chamadas cidades do agronegócio, transformando-se em lugares com 
variadas formas impulsionadas pelo agronegócio globalizado, que passam a desempenhar novas funções (ELIAS, 2006).

Os reflexos da reestruturação produtiva nos cerrados podem ser notados com 0 crescimento urbano acelerado e a conformação de cidades médias importantes que ocupam um papel fundamental na expansão e na operação do agronegócio. As cidades de Sinop (MT) e Rio Verde (GO) são alguns dos exemplos espalhados pelo país de cidades do agronegócio, pois são cidades que antes tinham um contingente populacional relativamente baixo, crescendo consideravelmente em poucos anos, criando uma nova dinâmica urbana. Os dados dos censos demográficos do IBGE entre 1980 a 2010 revelam a evolução populacional e a proporção do crescimento urbano em ambas as cidades (Tabela 1).

Tabela 1 - Evolução populacional e proporção do crescimento das cidades de Sinop-MT e de Rio Verde-GO entre $1980-2019$

\begin{tabular}{r|r|c|r|c}
\hline \multirow{2}{*}{ Ano } & \multicolumn{2}{|c|}{ Sinop-MT } & \multicolumn{2}{c}{ Rio Verde-GO } \\
\cline { 2 - 5 } & População Total & $\begin{array}{c}\text { Percentual de } \\
\text { crescimento }\end{array}$ & $\begin{array}{c}\text { População } \\
\text { Total }\end{array}$ & $\begin{array}{c}\text { Percentual de } \\
\text { crescimento }\end{array}$ \\
\hline 1980 & 19.891 & - & 74.699 & - \\
1991 & 38.374 & $94,70 \%$ & 96.309 & $28,90 \%$ \\
2000 & 74.831 & $95,00 \%$ & 116.552 & $21,00 \%$ \\
2010 & 113.099 & $51,10 \%$ & 176.424 & $51,30 \%$ \\
2019 & 142.996 & $26,43 \%$ & 235.647 & $33,57 \%$ \\
\hline
\end{tabular}

Os dados de 2019 são uma projeção.

Fonte: IBGE (1980, 1991, 2000, 2010a, 2019).

O município de Sinop, que tinha uma população total de 19.891 habitantes em 1980, atinge 113.099 habitantes em 2010, alcançando 142.996 pela previsão do IBGE para 2019. O município hoje é referência no estado do Mato Grosso em decorrência de sua produção agropecuária, sendo considerado a Capital do Agronegócio de Mato Grosso. Segundo levantamento feito pela Geofusion, empresa especializada em inteligência geográfica de mercado, Sinop está entre os 10 municípios do interior brasileiro que apresentou maior crescimento populacional (Sinop ficou em 9o lugar), entre 2010 e 2015, com crescimento populacional médio anual de 2,8\%. (DUARTE, 2016).

Outro exemplo de cidade que experimentou enorme crescimento populacional em decorrência do agronegócio foi a cidade de Rio Verde, pois o município sai de 74.699 habitantes, em 1980, para uma população de 176.424 habitantes em 2010 , sendo que a projeção do IBGE para 2019 aponta uma população de 235.647 habitantes. A vinda de novas empresas aumentou a oferta de emprego, atraindo grande contingente populacional, tornando o município um polo regional. Os números revelam o forte crescimento que continua a acontecer, apresentando um crescimento populacional projetado de $33 \%$ entre 2010 e 2019. 
O cenário atual indica o descolamento da relação migração-industrialização, migraçãoocupação de fronteira agrícola, migração-desconcentração industrial, migração-emprego, migração-mobilidade social no contexto atual da economia e da reestruturação produtiva, e:

As migrações internas possibilitaram a reorganização da população no território nacional, onde as vertentes da industrialização e das fronteiras agrícolas constituíram os eixos da dinâmica da distribuição espacial da população no âmbito interestadual, muito embora a primeira vertente detivesse os fluxos mais volumosos (BAENINGER, 2011, p. 73).

O processo histórico de ocupação das áreas de fronteira agrícola brasileira com a "agricultura moderna" reconfigura a fisionomia dos cerrados, impulsionando um processo de urbanização, com o surgimento de novas cidades e o crescimento exponencial de cidades preexistentes em decorrência das migrações. Essas novas dinâmicas são observadas também nos cerrados baianos, excepcionalmente nos casos das cidades de Barreiras e Luís Eduardo Magalhães.

\section{OS EFEITOS DA DINÂMICA MIGRATÓRIA NO PROCESSO DE URBANIZAÇÃO DOS CERRADOS BAIANOS}

Os cerrados do oeste da Bahia passam a atrair significativos contingentes populacionais de maneira intensa a partir dos anos 1970, quando se verificou uma enorme transferência de agricultores especializados no cultivo da soja do Rio Grande do Sul, do Paraná e de São Paulo. Em um segundo momento, vieram migrantes nordestinos, a maioria de baianos de outras regiões deslumbrados pelo "Novo Nordeste", rotulado de "Eldorado" da soja, que migraram para a região em busca de melhores oportunidades de trabalho.

Segundo Bezerra (2008, p. 163), "[...] a Região Nordeste tem sido uma das mais recentes fronteiras de expansão da sojicultora". Para Rogério Haesbaert (1997), o migrante sulista é lembrado como o principal agente dessa modernização agropecuária dos cerrados brasileiros, modernização esta que objetivava ampliar a produtividade agrícola, mas que também trouxe consigo grandes problemas ambientais, com a abertura de novas fronteiras, que foram incorporadas em grande parte pelo ao baixo preço da terra, o que levou à concentração da terra, à expropriação camponesa e acentuou a desigualdade socioespacial.

A ebulição econômica e o aumento brutal das desigualdades sociais com as migrações do sertão impulsionadas pelo mito do 'eldorado da soja' fazem com que muitos denominem estas áreas de o 'Novo' Nordeste, e alguns políticos já começam a articular novos recortes políticos-administrativos capazes de corroborar essa nova divisão territorial do trabalho, ditada pela modernização seletiva da agricultura (HAESBAERT, 1997, p. 382). 
Paralelamente ao PRODECER, a implantação da Companhia de Desenvolvimento dos Vales do São Francisco e do Parnaíba (CODEVASF) em 1974 foi importante, pois buscou atrair produtores rurais, com a implantação de perímetros irrigados próximos aos núcleos urbanos, caso da criação do primeiro projeto de colonização e irrigação na região oeste, o Perímetro Irrigado Barreiras-São Desidério. A intensificação dos fluxos migratórios em direção ao oeste baiano foi concentrada inicialmente na cidade de Barreiras, cidade mais estruturada da região, que já sediava importantes órgãos públicos estaduais e federais. No entanto, com a construção de grandes vias (BR-242), a região passou a contar com novas formas de conexões com os grandes centros urbanos (Salvador, Brasília e Goiânia), situação que provocou o surgimento de novos fluxos e possibilitou a formação de alguns povoados como Mimoso do Oeste, (que viria a se emancipar e se tornar a cidade de Luís Eduardo Magalhães), Novo Paraná e Bela Vista (todos em Barreiras); Roda Velha de Cima e Roda Velha de Baixo (em São Desidério) e Placas, Águas Claras e Rosário (em Correntina) (SANTOS, 2016).

Rios Filho (2017) considera que a difusão da "agricultura moderna" nos cerrados tem provocado uma nova organização de parte do território brasileiro, pautada, entre outras características, pelo surgimento de cidades funcionais no campo cada vez mais mecanizado, processo que se deu por conta da chegada dos migrantes sulistas, que se distanciaram de seu estado por motivos econômicos, tendo o propósito de buscar terras mais baratas e mais extensas. Foram eles que trouxeram junto com a abertura de novas fronteiras no cerrado baiano a modernização da agricultura, a exemplo das cidades de Barreiras e Luís Eduardo Magalhães.

Barreiras e Luís Eduardo Magalhães fazem parte do Território de Identidade Bacia do Rio Grande, localizado no Oeste baiano (Figura 1), sendo parte da mais recente fronteira agrícola do país. Elas representam hoje a principal área de produção agrícola moderna da região Nordeste, sobretudo de grãos, com destaque principal para a soja.

As cidades de Luís Eduardo Magalhães e Barreiras se destacam na Bahia como as áreas de cerrado que tiveram os resultados mais significativos quanto à expansão agrícola e o acelerado crescimento urbano nos cerrados do estado da Bahia. Ambas as cidades se destacam em relação à produção de soja e à extensão de suas zonas produtoras de culturas agrícolas secundárias, com destaque para o milho e o algodão. Os dados históricos da Produção Agrícola Municipal (PAM) permitem identificar a área plantada das principais culturas agrícolas nas últimas quatro décadas (Tabela 2).

Os dados da Tabela 2 revelam os altos índices de área plantada com soja em Barreiras, situando-a entre os maiores produtores de soja do estado da Bahia, com uma área plantada de 187.451 hectares, que interfere diretamente no valor de produção e na participação da renda agrícola, sendo a cultura agrícola com maior contribuição nas receitas 
do município. Apesar do peso da soja na economia, as culturas de milho e algodão, embora apresentem oscilações, têm se destacado secundariamente na produção de grãos e ocupam parcela importante na produção municipal.

Figura 1 - Barreiras e Luís Eduardo Magalhães: posição geográfica e configuração territorial
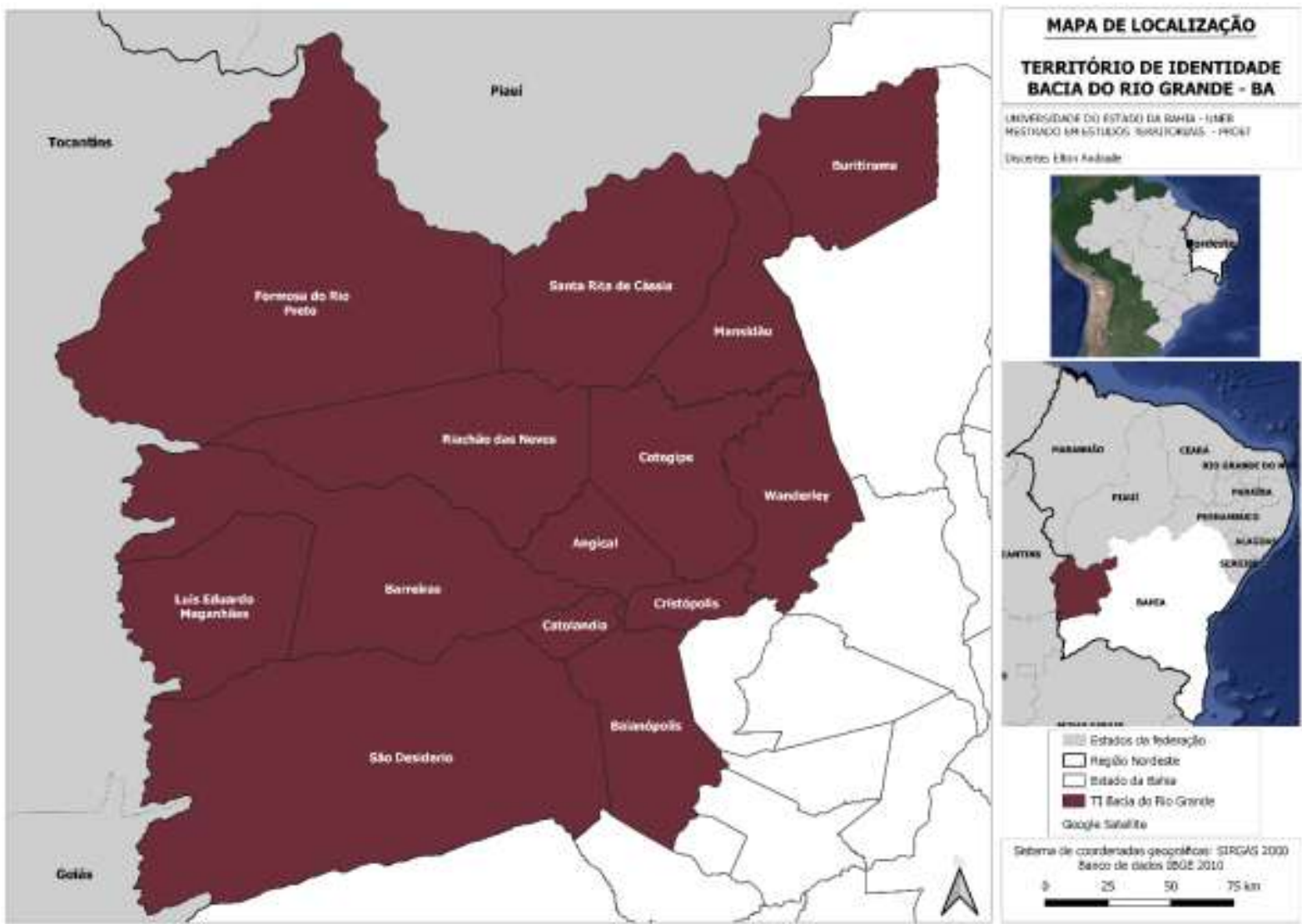

Fonte: elaborado pelos autores de IBGE (2010).

Tabela 2 - Evolução histórica da área plantada das principais culturas agrícolas em Barreiras e Luís Eduardo Magalhães

\begin{tabular}{|c|c|c|c|c|c|c|c|}
\hline \multirow{2}{*}{$\begin{array}{l}\text { Culturas } \\
\text { agrícolas }\end{array}$} & \multicolumn{4}{|c|}{$\begin{array}{l}\text { Barreiras: área plantada em hectares } \\
\text { (ha) }\end{array}$} & \multicolumn{3}{|c|}{$\begin{array}{l}\text { Luís Eduardo Magalhães: área plantada } \\
\text { em hectares (ha) }\end{array}$} \\
\hline & 1990 & 2001 & 2010 & 2018 & 2001 & 2010 & 2018 \\
\hline & & & 115.100 & & & 130.90 & 179.540 \\
\hline & & & & & & & \\
\hline Algodão & 510 & & 32.3 & 22.9 & & 9.551 & 12.100 \\
\hline & & & & & & 5.811 & 7.910 \\
\hline Mandioca & 3.168 & 4.000 & 2.600 & 300 & 520 & 280 & 100 \\
\hline
\end{tabular}

O município de Luís Eduardo Magalhães foi emancipado em 30 de março de 2000.

Fonte: elaborada pelos autores com base em IBGE (1990, 2001, 2010b, 2019).

Luís Eduardo Magalhães, apesar de apresentar números similares, se caracteriza pela alta produtividade de soja, todavia vem obtendo resultados destacados na participação da soja na renda agrícola e como produto principal no percentual de área plantada. Vale destacar, nos dois casos, os diferentes papéis desempenhados pela presença do café e da 
mandioca. O primeiro representa um grão historicamente cultivado em solos férteis, enquanto o segundo é uma cultura típica da agricultura familiar. Nota-se o crescimento do café como cultura que vem sendo introduzida, enquanto a mandioca perde espaço nesse processo de modernização agrícola.

O movimento agrícola impulsionou um intenso fluxo migratório, criando uma nova dinâmica urbana, pois cidades que antes tinham um contingente populacional relativamente baixo cresceram consideravelmente em poucos anos. Os dados dos censos entre 1970 a 2010 revelam a evolução populacional e a proporção do crescimento urbano tanto na cidade de Barreiras (Tabela 3), assim como em Luís Eduardo Magalhães (Tabela 4).

Tabela 3 - Evolução populacional da cidade de Barreiras. 1970-2010

\begin{tabular}{l|r|r|r|r|r|r}
\hline \multirow{2}{*}{ Ano } & População Total & $\begin{array}{l}\text { Percentual de } \\
\text { crescimento }\end{array}$ & \multicolumn{3}{l|}{ População Urbana } & \multicolumn{2}{l}{ População Rural } \\
\cline { 4 - 7 } & & \multicolumn{1}{l}{ Absoluta } & Relativa & Absoluta & \multicolumn{1}{l}{ Relativa } \\
\hline 1970 & 20.864 & - & 9.831 & $47,12 \%$ & 11.033 & $52,88 \%$ \\
1980 & 41.462 & $98,70 \%$ & 30.055 & $72,50 \%$ & 11.407 & $27,50 \%$ \\
1991 & 92.640 & $123,40 \%$ & 70.870 & $76,50 \%$ & 21.770 & $23,50 \%$ \\
2000 & 131.335 & $41,80 \%$ & 115.331 & $87,81 \%$ & 16.004 & $12,19 \%$ \\
2010 & 137.427 & $4,40 \%$ & 123.741 & $90,04 \%$ & 13.686 & $9,96 \%$ \\
\hline
\end{tabular}

Fonte: elaborada pelos autores de: IBGE (1970, 1980, 1991, 2000, 2010a).

Tabela 4 - Evolução populacional da cidade de Luís Eduardo Magalhães - 1991-2010

\begin{tabular}{l|l|l|l|l|l|r}
\hline \multirow{2}{*}{ Ano } & População & Percentual de & \multicolumn{3}{|l|}{ População Urbana } & \multicolumn{3}{|l}{ População Rural } \\
\cline { 4 - 8 } & Total & crescimento & Absoluta & Relativa & Absoluta & \multicolumn{1}{l}{ Relativa } \\
\hline 1991 & 6.600 & - & 0 & $0 \%$ & 6.600 & $100 \%$ \\
2000 & 18.757 & $184,2 \%$ & 15.699 & $83,70 \%$ & 3.058 & $16,30 \%$ \\
2010 & 60.105 & $220,4 \%$ & 54.881 & $91,30 \%$ & 5.224 & $8,70 \%$ \\
\hline
\end{tabular}

Fonte: elaborada pelos autores de: IBGE (1991, 2000, 2010a).

Os dados apresentados nas Tabelas 3 e 4 revelam pelo menos três processos fundamentais para avaliarmos o impacto da ocupação dos cerrados baianos: o forte crescimento populacional dos dois municípios, o intenso processo de urbanização e o surgimento de uma nova cidade.

O município de Barreiras, que tinha uma população total de 20.684 habitantes em 1970, atinge 137.427 habitantes em 2010, com projeção de 155.439 habitantes para o ano de 2019. Trata-se de um exponencial crescimento populacional da ordem de $651 \%$ em apenas cinco décadas. Outra característica revelada com os dados são os números crescentes de população urbana, pois, até o início da década de 1970, a população rural era levemente superior, atingindo a população urbana o expressivo patamar de $90,04 \%$ em 2010. 
Outra consequência foi o surgimento de um novo núcleo urbano na região, a cidade do agronegócio de Luís Eduardo Magalhães, cujos dados revelam um intenso crescimento, pois o município sai de 18.757 em 2000 (ano de sua emancipação) para 87.519 habitantes (conforme projeção do IBGE) no ano de 2019, um crescimento da ordem de superior a $367 \%$ em apenas duas décadas. A cidade deixa de ser um povoado com 6.600 habitantes em 1991, para se tornar uma cidade média em menos de 30 anos. Deixa de ser um povoado formado por população essencialmente rural, para se tornar uma cidade com taxa de população urbana que atingiu o patamar de 91,30\% em 2010.

Uma importante questão se impõe com esses números: as cidades apresentam um elevado crescimento urbano em decorrência dos intensos fluxos migratórios que decorrem da atração gerada pela agricultura moderna, mas a população rural vem experimentando acentuado decréscimo a partir de 1991, revelando fluxos migratórios rurais-urbanos, como também fluxos inter-regionais, como veremos mais à frente, e a constatação do desemprego estrutural que a agricultura moderna concentradora de terra e de riqueza impõe.

A amostra do censo demográfico mais recente, correspondente ao ano de 2010, informa que Barreiras tinha 14.072 imigrantes no ano de 2010. Se cotejarmos este número com os dados da origem geográfica da população residente no município em 2010, verificase que $14,08 \%$ dos fluxos migratórios são intrarregionais, isto é, são originários da região Nordeste, e, dos $85,2 \%$ restantes, destacam-se os fluxos migratórios inter-regionais, predominando os fluxos da região Centro-Oeste $(31,3 \%)$, do Sudeste $(23,5 \%)$ e do Sul $(20,1 \%)$ (Tabela 5).

Tabela 5 - Origem da população migrante residente em Barreiras-BA - 2010

\begin{tabular}{l|r|r|}
\hline Lugar de Nascimento & População absoluta & População relativa \\
\hline Região Nordeste & 2.079 & $14,8 \%$ \\
Região Centro-oeste & 4.412 & $31,3 \%$ \\
Região Sudeste & 3.307 & $23,5 \%$ \\
Região Sul & 2.823 & $20,1 \%$ \\
Região Norte & 466 & $3,3 \%$ \\
Estrangeiros & 88 & $0,6 \%$ \\
Sem especificação & 897 & $6,4 \%$ \\
\hline Total & $\mathbf{1 4 . 0 7 2}$ & $\mathbf{1 0 0 \%}$ \\
\hline
\end{tabular}

Fonte: elaborada pelos autores de: IBGE (2010a).

A Tabela 5 revela a origem dos fluxos migratórios para cidade de Barreiras. A literatura acadêmica (ELIAS, 2006; HAESBAERT, 1997; MONDARDO, 2012) enfatiza a importância dos fluxos oriundos do Sudeste e Sul do Brasil, cuja afirmação ficou reforçada pelos dados do último censo demográfico. Aqui vale destacar a importância da migração no âmbito dos cerrados, pois os dados revelam que os movimentos migratórios do Centro-Oeste para Barreiras são os mais significativos. 
O Oeste Baiano, especialmente Barreiras, é uma área na qual o crescente processo de urbanização se deve diretamente ao agronegócio. Como é notório, a associação dos resultados apresentados nas Tabelas 3 e 5 demonstra, em certa medida, que o processo de modernização agrícola fez com que grandes contingentes populacionais fossem atraídos para a região, além dos migrantes do centro-sul, que vieram em busca de terra e de trabalho. Barreiras como principal núcleo urbano se configura territorialmente também como espaço de convergência e circulação de fluxos migratórios, na medida em que a modernização e a expansão de novas atividades vinculadas à agropecuária promoveram o processo de urbanização, cujos vínculos principais se devem às inter-relações cada vez maiores entre campo e cidade.

A amostra de Luís Eduardo Magalhães indica que o município tinha 21.318 migrantes, com base nos dados do censo demográfico de 2010 (Tabela 6). A observação dos dados da origem geográfica da população residente revela que, diferentemente de Barreiras, os fluxos intrarregionais são mais representativos individualmente, pois $35,7 \%$ dos migrantes residentes em Luís Eduardo Magalhaes são originários da região Nordeste. No caso desta cidade, os fluxos migratórios originados na região Sul são significativos, atingindo $29,6 \%$ da população migrante residente no município.

Tabela 6 - Amostra da origem da população residente em Luís Eduardo Magalhães-BA

\begin{tabular}{l|r|r|}
\hline Lugar de Nascimento & Quantidade de pessoas & População relativa \\
\hline Região Nordeste & 7.618 & $35,7 \%$ \\
Região Centro-oeste & 2.685 & $12,6 \%$ \\
Região Sudeste & 2.468 & $11,6 \%$ \\
Região Sul & 6.310 & $29,6 \%$ \\
Região Norte & 1.231 & $5,8 \%$ \\
Estrangeiros & 65 & $0,3 \%$ \\
Sem especificação & 941 & $\mathbf{4 , 4 \%}$ \\
\hline Total & $\mathbf{2 1 . 3 1 8}$ & $\mathbf{1 0 0 \%}$ \\
\hline
\end{tabular}

Fonte: elaborada pelos autores de IBGE (2010a).

Se considerarmos que Luís Eduardo Magalhaes era um povoado com 6.600 habitantes em 1991, tendo atingido uma população de 60.105 habitantes em 2010, podemos deduzir que isso foi devido ao substancial fluxo migratório, não ao crescimento vegetativo. Tomando como base a população do município em 2010, ou seja, 60.105 habitantes (Tabela 4), e confrontando com o total de migrantes da Tabela 6, isto é, 21.318 habitantes, concluímos que $35,47 \%$ da população residente no município é composta por migrantes, sendo que $64,3 \%$ oriunda de outras regiões brasileiras.

Apesar de apresentar similaridades com Barreiras, Luís Eduardo Magalhães tem características específicas. Com o avanço do processo de restruturação produtiva e a reorganização do espaço urbano e a ampliação do cultivo de soja nos cerrados baianos, a necessidade da emergência de um centro urbano mais próximo à zona produtora elevou a 
posição de Luís Eduardo Magalhães, cidade que vai gradativamente substituindo a cidade de Barreiras (núcleo urbano mais antigo e importante do Oeste d Bahia) como localidade central no arranjo produtivo do agronegócio da soja, com melhor localização e melhor posição de centralidade urbana.

Esses imigrantes se tornaram os principais agentes da emancipação política do município de Luís Eduardo Magalhães ocorrida no ano 2000. Com isso, muitos migrantes deixaram de ser agricultores para se tornarem empresários agrícolas nos cerrados. De acordo com Elias (2006), estes são signos da formação de uma classe média agrícola, cuja residência passa a ser a cidade próxima ao espaço agrícola no qual se desenvolve a atividade produtiva, podendo em grande medida serem chamadas de cidades do agronegócio.

Nas cidades mais influenciadas pela dinâmica da agricultura moderna, observa-se a coexistência de conteúdos urbanos e rurais na conformação das cidades, componente fundamental para compreender os processos socioespaciais e entender como se estrutura e se organiza um comércio voltado para as demandas do agronegócio. Trata-se de atividades comerciais, logo, urbanas, mas completamente implicadas com o desenvolvimento da agricultura moderna nos cerrados.

Nesse sentido, muitas empresas ligadas ao agronegócio globalizado (Figuras 2 e 3), se instalaram nas cidades do Oeste Baiano. As grandes empresas, via de regra, oriundas do Centro-Sul, quase sempre se deslocaram para a região Oeste da Bahia dispondo de instrumentos técnicos e tecnológicos que aumentaram seu poder, mobilizando importantes recursos de capital para esse espaço, tanto em termos de instalações, maquinários e equipamentos, quanto em estoques armazenados ou em infraestrutura e, consequentemente, gerando atração de mão de obra para essas atividades.

Figuras 2 e 3 - Representação da disseminação de empresas de natureza agrícola na cidade de Luís Eduardo Magalhães e Barreiras, respectivamente

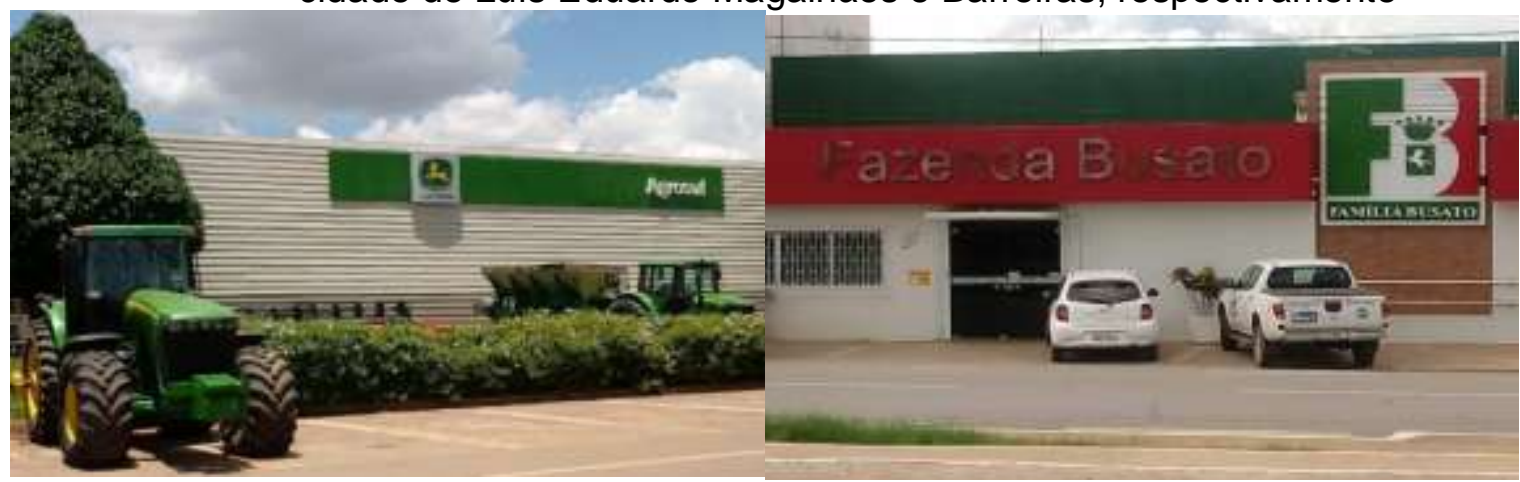

Fonte: acervo dos autores, 2020.

No entanto, a difusão do agronegócio tem-se traduzido não apenas na reestruturação produtiva da agropecuária, mas no reforço de históricos problemas regionais, como a 
concentração fundiária e de renda, a desarticulação dos pequenos produtores e a expansão da monocultura, bem como na criação de novos problemas, a exemplo da privatização da água, da degradação ambiental, da exploração da mão de obra do campo e da intensa urbanização (OLIVEIRA, 2015).

As formas e os processos espaciais se refletem na segregação socioespacial, contrapondo os condomínios de classe média com os bairros periféricos no zoneamento das cidades. Em ambas as cidades, proliferam os condomínios fechados e a crescente verticalização (Figura 4), com a formação de condomínios residenciais privados de alto padrão, decorrentes da dinâmica econômica do agronegócio, que estrutura uma classe capaz de adquirir e sustentar um mercado imobiliário da região.

No entanto, essa realidade se contrapõe à existência de bairros que sofrem com a precariedade nas habitações (Figura 5) e da infraestrutura de saneamento, lugares destinados à população de baixa renda. É notável na paisagem o crescimento desigual dos seus espaços urbanos por um processo que fortaleceu os grandes proprietários de terras e os empresários, contrastando com a pobreza de grande parte da população que depende dos empregos mal remunerados das atividades de comércio, serviços e indústria, vinculadas à agricultura.

Figura 4 - Representação da verticalização Figura 5 - Realidade desigual em bairro crescente em Barreiras-BA

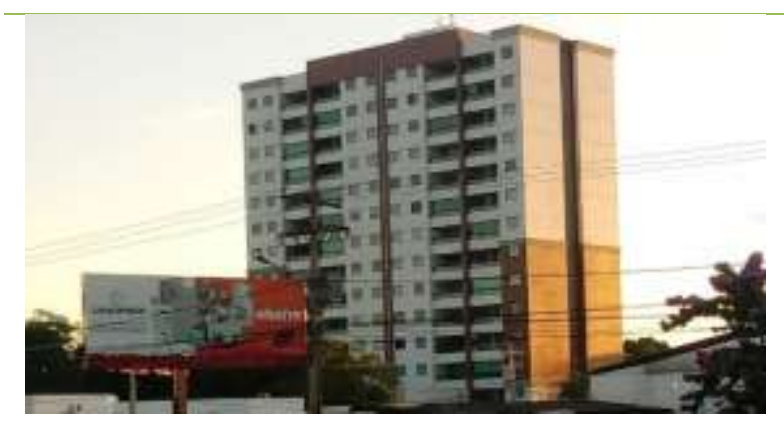
periférico em Luís Eduardo Magalhães

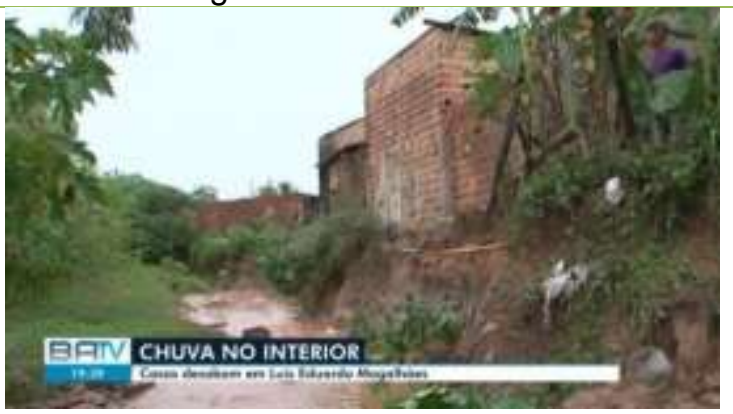

Fonte: acervo dos autores (2020).

Fonte: Chuva..., 2019.

A despeito dos processos de crescimento de algumas cidades, verifica-se que o Oeste baiano se constitui em um espaço de baixa densidade de centros urbanos, exigindo grandes deslocamentos para a obtenção de serviços e infraestrutura. A expansão do comércio e dos serviços, estimulada pelo agronegócio, pode promover o desenvolvimento de algumas cidades e o surgimento de novas aglomerações urbanas no Oeste, de modo a resultar em uma redefinição do próprio espaço urbano regional (RIOS FILHO, 2012), mas ainda não repercutiu na criação de uma densa e articulada rede de cidades.

As novas organizações espaciais resultam da relação de interdependência entre agricultura, indústria, população, urbanização e política. Esta interação promove o 
funcionamento, a estruturação e a dinâmica econômica da organização espacial atual do Oeste da Bahia (GÓES, 2011).

\section{CONSIDERAÇÕES FINAIS}

A reestruturação produtiva nos cerrados se efetivou pela ação do Estado, por meio dos investimentos em pesquisas agropecuárias e do financiamento da iniciativa privada para ocupação das chamadas áreas de fronteira agrícola. As ações da EMBRAPA e do PRODECER foram decisivas para o desenvolvimento de tecnologias que viabilizaram a expansão agrícola nos cerrados, com a introdução da chamada "agricultura moderna", engendrando a atração de expressivos fluxos migratórios.

As migrações passaram a desempenhar papel fundamental na dinâmica dos cerrados brasileiros, em particular dos cerrados baianos. Os fluxos migratórios mais numerosos foram os de trabalhadores, predominantemente deslocamentos intrarregionais, mas não podem ser desconsiderados os fluxos inter-regionais de sulistas, que vieram como agentes da modernização econômica.

Um dos efeitos mais significativos dos fluxos migratórios que contribuíram para o processo de ocupação dos cerrados baianos foi o crescimento acelerado de cidades, transformando cidades pequenas em cidades médias em poucas décadas, caso da cidade de Barreira. Verificou-se também o surgimento de novas cidades, como Luís Eduardo Magalhães, que experimentou um crescimento populacional de quase dez vezes em apenas duas décadas. Essas cidades, embora estruturadas em torno do agronegócio, apresentam uma intensificação do processo de urbanização. Barreiras, como principal polo regional, se coloca também como sede de importantes órgãos estatais estaduais e federais. No entanto, Luís Eduardo Magalhaes tem sua dinâmica urbana centrada nas atividades do agronegócio, seja no segmento agrícola, industrial e comercial.

Um reflexo perverso da modernização agrícola é a produção de segregação socioespacial, pois se formou uma minoria de privilegiados, que vive em condomínios fechados de alto padrão, contrastando com a grande maioria de trabalhadores, que vive em bairros com enorme precariedade de infraestrutura. As repercussões da chamada "agricultura moderna" demandam um permanente esforço científico para o aprofundamento das reflexões críticas sobre seus efeitos sociais.

\section{REFERÊNCIAS}

ALVES, Vicente Eudes Lemos. Mobilização e modernização nos cerrados piauienses: formação territorial no império do agronegócio. Tese (Doutorado em Geografia) - Faculdade de Filosofia, Letras e Ciências Humanas, Universidade de São Paulo, SP, São Paulo, 2006. 
BAENINGER, Rosana Migrações internas no Brasil século 21: evidências empíricas e desafios conceituais. In: CUNHA, José Marcos Pinto da. (org.). Mobilidade especial da população: desafios teóricos e metodológicos para o seu estudo. Campinas: Nepo/Unicamp, 2011. p. 71-93.

BECKER, Olga Maria Schild. Mobilidade espacial da população: conceitos, tipologia, contextos. In: CASTRO, Iná Elias de; PAULO, Cesar da Costa; CORRÊIA, Roberto Lobato (orgs.). Explorações geográficas: percursos no fim do Século. Rio de Janeiro: Bertrand Brasil, 1997. p. 319-367.

BEZERRA, Juscelino Eudâmidas. Agronegócio e a nova divisão social e territorial do trabalho agropecuário formal no Nordeste. 2008. Dissertação (Mestrado em Geografia) Universidade Estadual do Ceará, Fortaleza, 2008.

BRANDÃO, Paulo Roberto Baqueiro. A formação territorial do Oeste Baiano: a constituição do "Além São Francisco" (1827-1985). Geotextos, Salvador, BA, v. 6, p. 35-50, 2010.

CHUVA provoca desabamento de casas na cidade na cidade de Luís Eduardo Magalhães. G1 Globo. BATV, Salvador, BA, 26 mar. 2019. 1 vídeo (2:44 min). Disponível em: http://g1.globo.com/bahia/bahia-agora/videos/t/edicoes/v/chuva-provoca-desabamento-decasas-na-cidade-de-luis-eduardo-magalhaes/7488232/. Acesso em: 30 mar. 2020.

DUARTE, Valéria. Novo estudo da Geofusion revela informações sobre o interior do Brasil. Geofusion, São Paulo, SP, 21 jun. 2016. Disponível em: https://blog.geofusion.com.br/novoestudo-da-geofusion-revela-informacoes-sobre-o-interior-do-brasil. Acesso em: 2 jun. 2020.

ELIAS, Denise. Ensaios sobre os espaços agrícolas de exclusão. Revista Nera, Presidente Prudente, SP, n. 8, p. 29-51, 2006.

GAUDEMAR, Jean-Paul de. Mobilité du travail et accumulation du capital. Paris: Maspero, 1976.

GÓES, Liliane Matos. Abordagem sistêmica aplicada aos complexos agroindustriais da soja e do algodão no território do extremo oeste da Bahia. 2011. Dissertação (Mestrado em Geografia) - Universidade Estadual de Campinas, SP, Campinas, 2011.

HAESBAERT, Rogério. Desterritorialização e identidade: a rede "gaúcha" no Nordeste. Niterói: EDUFF, 1997.

HARVEY, David. Condição pós-moderna. São Paulo: Edições Loyola, 1992.

IBGE. Censo demográfico. Rio de Janeiro, RJ: IBGE, 1970. Disponível em: http://www.ibge.gov.br. Acesso em: 17 fev. 2020.

IBGE. Censo demográfico. Rio de Janeiro, RJ: IBGE, 1980. Disponível em: http://www.ibge.gov.br. Acesso em: 17 fev. 2020.

IBGE. Censo demográfico. Rio de Janeiro, RJ: IBGE, 1991. Disponível em: http://www.ibge.gov.br. Acesso em: 17 fev. 2020.

IBGE. Censo demográfico. Rio de Janeiro, RJ: IBGE, 2000. Disponível em: http://www.ibge.gov.br. Acesso em: 17 fev. 2020.

IBGE. Censo demográfico. Rio de Janeiro, RJ: IBGE, 2010a. Disponível em: http://www.censo2010. ibge. gov.br. Acesso em: 11 mar. 2020.

IBGE. Produção agrícola municipal. Rio de Janeiro, RJ: IBGE, 1990. Disponível em: https://biblioteca.ibge. gov.br/index.php/biblioteca-catalogo?view=detalhes\&id=766. Acesso em: 2 maio 2020.

IBGE. Produção agrícola municipal. Rio de Janeiro, RJ: IBGE, 2001. Disponível em: https://biblioteca.ibge. gov.br/index.php/biblioteca-catalogo?view=detalhes\&id=766. Acesso em: 2 maio 2020. 
IBGE. Produção agrícola municipal. Rio de Janeiro, RJ: IBGE, 2010b. Disponível em: https://biblioteca.ibge. gov.br/index.php/biblioteca-catalogo?view=detalhes\&id=766. Acesso em: 2 maio 2020.

IBGE. Produção agrícola municipal. Rio de Janeiro: IBGE, 2019.

KLEIN, Maria Regina; MASSUQUETTI, Angélica; SPRICIGO, Gisele. Migrações internas: um estudo do município de Novo Hamburgo (RS). Ensaios FEE, Porto Alegre, RS, v. 33, n. 2, p. 603-632, 2012.

LEE, Everett S. Uma teoria sobre a migração. In: MOURA, Hélio A. de (coord.). Migração interna: textos selecionados. Fortaleza: BNB/ETENE, 1980. p. 89-114.

MARANDOLA JÚNIOR, Eduardo. Mobilidades contemporâneas: distribuição espacial da população, vulnerabilidade e espaços de vida nas aglomerações urbanas. In: CUNHA, José Marcos Pinto da (org.). Mobilidade espacial da população: desafios teóricos e metodológicos para o seu estudo. Campinas: Nepo/Unicamp, 2011. p. 95-115.

MARANDOLA JÚNIOR, Eduardo; DAL GALLO, Priscila Marchiori. Ser migrante: implicações territoriais e existenciais da migração. Revista Brasileira de Estudos de População, v. 27, n. 2, p. 407-424, 2010.

MONDARDO, Marcos Leandro. A "territorialização" do agronegócio globalizado em Barreiras-BA: migração sulista, reestruturação produtiva e contradições sócioterritoriais. Revista Nera, Presidente Prudente, SP, n. 17, p. 112-130, 2012.

OJIMA, Ricardo; MARANDOLA JÚNIOR, Eduardo. Mobilidade populacional e um novo significado para as cidades: dispersão urbana e reflexiva na dinâmica regional não metropolitana. Revista Brasileira de Estudos Urbanos e Regionais, Recife, PE, v. 14, n. 2, p. 103-116, 2012.

OLIVEIRA, Maria Aparecida Brito. Do sertão São Franciscano ao Oeste na Bahia: uma análise da trajetória de políticas do Estado no processo de formação territorial (1889-2014). 2015. Dissertação (Mestrado em Geografia) - Instituto de Geociências, Universidade Federal da Bahia, 2015.

RACZYNSKI, Dagmar. La movilidad territorial de la poblacion en America Latina: perspectivas de analisis y lineamientos de investigacion. In: CONGRESSO LATINOAMERICANO DE POBLACION Y DESARROLLO, 1983, Cidade do México, México. Cidade do México: Universidad Nacional Autónoma de México, 1983. Anais [...]. p. 863-892.1983.

RAVENSTEIN, Ernest. G. As leis das migrações. In: MOURA, Hélio A. de (coord.). Migração interna: textos selecionados. Fortaleza: BNB/ETENE, 1980. p. 25-88.

RIGOTTI, José Irineu Rangel. VII. Dados censitários e técnicas de análise das migrações no Brasil: avanços e lacunas. In: CUNHA, José Marcos Pinto da. (org.). Mobilidade espacial da população: desafios teóricos e metodológicos para o seu estudo. Campinas: Nepo/Unicamp, 2011. p. 141-155.

RIOS FILHO, Jorge Ney Valois. As "novas" formas espaciais urbanas da agricultura: as cidades do agronegócio do Oeste Baiano e a cidade-campo em Salvador/BA. 2017. Tese (Doutorado em Geografia) - Instituto de Geociências, Universidade Federal da Bahia, BA, Salvador, 2017.

RIOS FILHO, Jorge Ney Valois. Segregação socioespacial na cidade do agronegócio de Luís Eduardo Magalhães (BA). 2012. 208 f. Dissertação (Mestrado em Geografia) Instituto de Geociências, Universidade Federal da Bahia, BA, Salvador, 2012.

SALIM, Celso Amorim. Migração: o fato e a controvérsia teórica. In: ENCONTRO NACIONAL DE ESTUDOS POPULACIONAIS, 8., Campinas, SP. Anais [...].Campinas: ABEP, 1992, p.119-144. 
SANTOS, Clóvis Caribé Menezes dos. Oeste da Bahia: modernização com (des)articulação econômica e social de uma região. Tese (Doutorado em Ciências Sociais) - Universidade Federal da Bahia, BA, Salvador, BA, 2007.

SANTOS, Camila Dutra dos. Difusão do agronegócio e reestruturação urbano-regional no Oeste Baiano. GeoTextos, Salvador, BA, v. 12, n. 1, p. 157-181, 2016.

SINGER, Paul. Migrações internas: considerações teóricas sobre o seu estudo. In: MOURA, Hélio A. de (coord.). Migração interna: textos selecionados. Fortaleza: BNB/ETENE, 1980. p. 211-244.

TODARO, Michael P. A Model of Labour Migration and Urban Unemployment in Less Developed Countries. American Economic Review, Nashville, Tenn, US, v. 59, n. 1, p.138148, 1969.

WESZ JUNIOR, Valdemar João. O mercado da soja no Brasil e na Argentina: semelhanças, diferenças e interconexões. Século XXI: Revista de Ciências Sociais, Santa Maria, RS, v. 4, n. 1, p. 114-161, 2014.

WOOD, Charles $\mathrm{H}$. Equilibrium and historical-structural perspectives on migration.

International Migration Review, New York, US, v. 16, n. 2, p. 298-319, 1982.

Recebido: julho de 2020. Aceito: setembro de 2020. 